\title{
Introduction: Reading CanLit in Spain
}

\section{Pilar Somacarrera}

Returning from a research stay in Canada in July 2010, I took a taxi at the Madrid-Barajas airport and the taxi driver asked me where I was coming back from. When I replied that I was returning from Toronto, he asked me if Toronto was in the United States, which surprised me as the city had hosted the G20 just a few days earlier. This simple anecdote is symptomatic of the lack of knowledge of the average Spanish citizen about Canada. And if most Spaniards cannot place Canada's cities on a map, they have even greater difficulties with mapping Canada's culture and, more specifically, its literature.

Starting from the premise that translation is an activity of vital importance in the context of the globalization of cultural markets, the genesis of this collection originated in two ideas about the new global role of CanLit and its local reception in my country of origin and residence, Spain. First, that the study of the relationship between translation of English-Canadian authors and ideological factors would be especially interesting in the case of Canada and Spain, given that these two countries are still relatively ignorant of each other. $\mathrm{A}$ factor which clearly influences Canada's "invisibility" in Spain is that Canadian cultural products still exist in the shadow of the United States, a much more visible country in the publishing and media industry (Somacarrera, 2009).

Secondly, Canlit has assumed a transnational and global currency (Kamboureli, 2007) and the Canadian Government is eager to capitalize on the popularity and economic success of Canadian literature abroad (Moss and Sugars, 2009). Furthermore, the complicated relationship between Canadian literature as circulated within Canada and Canadian literature as an international commodity depends upon the external validation of Canadian cultural products and the writers who produce them (Roberts, 2011). However, most books and journals about Canadian Literature focus on CanLit in Canada and not elsewhere 
in the world. In addition, except for one or two exceptions (von Flotow and Nischik,2007) the academic production on CanLit contains no references to the translation of Canadian writing which is currently playing a vital role in its dissemination around the world.

The overall objective of the collection is to assess the transference, reception and promotion of CanLit in translation in Spain and to determine its impact on the Spanish reading public, dating principally from the inception of the Spanish Association for Canadian Studies in 1988, and gauging its evolution up to the present. To this end, we have consulted databases (the online catalogue of the Spanish National Library, the ISBN -The Spanish International Standard Book Number- and the Index Translationum), as well as a corpus of a selection of media texts about English-Canadian writers, ranging from paratextual material like cover blurbs, prefaces and introductions to Spanish editions of Canadian books to photographs, caricatures, reviews, interviews, newspaper articles, internet blogs and publishers' web pages. We have also interviewed and sent questionnaires to translators and relevant figures on the Spanish literary scene.

Three aspects of the cultural transfer of CanLit into Spain will be addressed: the selection, the translation and the reception of Canadian authors, all contextualized in the socio-political and cultural coordinates of the target country and its readership. The issue of the selection of Canadian texts and authors is examined in all the chapters of this collection, addressing why certain CanLit authors and texts have been selected for translation, promotion and/or teaching and why others have been excluded. We also try to unveil the sociological, aesthetic, economic and ideological considerations which have entered this selection process. In what concerns the choice of texts and authors, the absences are sometimes more significant than the presences. We inquire into why some genres (fiction) are preferred over others (poetry, non-fiction) and why some are still trying to make their way into the system (drama written in English).

Sometimes, albeit rarely, the factor which influences the decision of what to translate is the translator. The collection discusses the role of these often neglected agents, the Spanish-English translators, especially in what relates to their motivation and challenges in the process of translating the literature of a country that many Spaniards are not familiar with. The volume also deals with the factors that encourage or hinder the reading and promotion of Canadian literature in Spain. These include the role and influence of institutions (political and commercial), publishers and their marketing systems, literary critics, reviewers and academics, as well as the significance of new technologies and different types of media (print, electronic, official, social, personal) with regard to the success of particular genres and authors. In the context of the marketing of literature, special attention will be paid to literary prizes and their role in the dissemination of Canadian literature in Spain. Finally, stereotypical beliefs 
and current images of Canada in Spain, the role of cultural branding and the interaction of the Canadian and Spanish literary systems also form part of the main arguments of the collection.

As I mentioned before, this work attempts to integrate the immediacy of information and sighting of trends and effects with a cohesive and encompassing use of a variety of classical and current theoretical frameworks. These include postcolonial literary theory, translation studies theory, sociological theory like Pierre Bourdieu's, reader response theory, cosmopolitanism as formulated by Emmanuel Lévinas and Siby K. George, studies on the marketing of literature, literary prizes and best-sellers, and recent studies on the new situation of CanLit as a discipline, like the projects initiated by Smaro Kamboureli and the TransCanada Institute at the University of Guelph.

Before going on to describe the structure of the collection, on, one aspect about its scope should be clarified. The literature of French-speaking Canada has been deliberately excluded from this volume for several reasons. First, the permanent comparison and identification in Spain of English-Canadian and US literature - which is understandable since the two literary traditions share the same language - is not a feature of the reception of the literature in French. ${ }^{1}$ Secondly, the exclusion from this volume of literature written in French is also intentional because the conditions governing the translation and dissemination of this literature in Spain differ considerably from those at work for the EnglishCanadian. These conditions are related to the hegemonic position of English in the global cultural market, which determines what is and what is not "international" on the Spanish publishing scene, often at the cost of promoting national stereotypes (Magrinyà, 2010). Thirdly, the chosen comparative approach would have been very difficult to follow in dealing with three different cultures (Spain, English-Canada and Quebec).

The book is divided into four sections. The title of the first section, "Terra (In)cognita," was suggested by Bernd Dietz's description of Canadian culture as a "terra incognita" in his 1985 anthology of contemporary Anglo-Canadian poetry. As JoAnne Neff (1999) points out, the North and the Arctic - geographical locations which most Spaniards associate with Canada - are usually perceived as a "terra incognita," not only unknown, but also unknowable. This unknowability characterized the dissemination of CanLit in Spain at beginning of the period studied in this volume (1988-2010), but the situation is gradually changing, owing to the various factors analysed in this collection.

1 As will be analysed in several chapters of this collection, the influence of the US on Canada is inevitable due to the geographical proximity of the countries, their sharing of the same language and the cultural and economic power of the U.S. 
The chapters of the first section, "Contextual and Institutional Coordinates of the Transference of Anglo-Canadian Literature into Spain" and "Cosmopolitans at Home: the Spanishness of Canadian Women Writers," deal with this lack of knowledge about Canada and its authors in Spain and the various techniques which publishers and reviewers have deployed to make Spanish readers familiar with it.

The second section, "Nation and Translation," which includes chapters "Translation, Nation Branding and the Indo-Chic: the Circulation and Reception of South Asian Canadian Fiction in Spain" and "Canadian into Catalan: the Translation of Anglo-Canadian Authors in Catalonia," addresses issues of nation branding and cultural nationalism. The first of these chapters discusses how South Asian Canadian writers are used for the branding of Canada as a multicultural nation, whereas the following one explores the co-existence of two languages and cultures (Catalan and Spanish) in Catalonia, and the extent to which - even if only indirectly - the solid relations of this autonomous community with Quebec have influenced the publication of Canadian authors. The third section of the volume ("Of Prizes and Passions"), including chapters "A Prince of Asturias Award for the Queen of Canadian Letters: Reading Margaret Atwood in Spain" and "A Spanish Passion for the Short Story: Reader Responses to Alice Munro in Web 2.0," deals with two writers (Atwood and Munro) who have obtained considerable symbolic capital in Spain thanks to the awards they have received and the various ways in which they have been perceived by the Spanish media and reading public. Finally, we look towards the future of CanLit in Spain in the last section of the volume ("Gen X: Culture and Pedagogy"), in which Chapter 7 addresses the dissemination of Douglas Coupland's works in print media and in various literary circles, and Chapter 8 deals with the development of CanLit as a field of study at the university level in Spain.

Chapter 1 ("Contextual and Institutional Coordinates of the Transference of Anglo-Canadian Literature into Spain") provides abundant information about the context of reception and the different institutional agents which have taken part in the process of transference. After some considerations about the importance of the Spanish language in global publishing, I offer, firstly, an overview of the social, political and economic coordinates of Spain since General Franco's death in 1975 until the present day. Secondly, I discuss some of the factors that hinder and/or promote the dissemination of Canadian works in Spain, such as the low reading rate of the Spanish population, publication in the three co-official languages (Catalan, Basque and Galician) and the important role of Spanish publishers and Spanish literary supplements and their reviewers. Against this background, the success of the strategies of Canadian government agencies (DFAIT, Canada Council, Spanish Association and Canadian Studies Foundation) is measured. The chapter ends with an overview of the most published authors and a discussion of how English-Canadian poetry has fared in Spain through the brief case studies of three relevant authors: Leonard Cohen, Margaret Atwood and Anne Carson. 
Chapter 2 ("Cosmopolitans at Home: the Spanishness of Canadian Women Writers") by Nieves Pascual deals with the reception of Canadian women writers in Spain. The nineteen eighties saw an unprecedented proliferation of women writers in the Spanish literary system in spite of the late penetration of feminist theory (Prieto and Langa, 2007) which was followed by the transference of Canadian women writers through translation. The title of this chapter refers to the ways in which writers like Elizabeth Smart, Margaret Laurence, Mavis Gallant, Carol Shields, and Anne Michaels have been imported as icons of cosmopolitanism and later acculturated into the Spanish target literary system. This kind of cosmopolitanism is unchallenged by the foreign and affirms the ideology and values of the target culture, in this case the Spanish one. Nieves Pascual's analysis is preceded by an overview of translation studies theories (by Jacques Derrida, Lawrence Venuti and Carol Maier) which use metaphors of violence to refer to the abuse exerted both on the source and target texts during the process of translation. In order to explain how this violence can be avoided, Pascual draws on Emmanuel Lévinas's ideas about identity and their phenomenological rewriting by the Indian philosopher Siby K. George, who sees identity as something porous and transcendent. Thus, cultural proximities shape the notion of the self, which, following Lévinas's argument, must inevitably integrate the Other.

Pascual focuses on the paratexts that surround the translated texts of the Canadian women authors chosen for her study: firstly, the editorial policies of the Spanish publishers associated with these authors as they appear on the internet; secondly, reviews and blurbs by professional critics appearing in newspapers and in the invitation cards to a reading series by Canadian women writers which took place in Madrid at the turn of the twentieth century. In a lucid analysis which could be applied to almost all the writers studied in this volume, the author's conclusions are three-fold: (a) that the symbolic capital of a Canadian literary work in Spain depends on the accumulation of cosmopolitanism; (b) that Canada is translated by and into Spanish culture as a cosmopolitan culture; and (c) that it is through cosmopolitanism that the work's specificity is denied and ours is confirmed.

The first of the two chapters of the second section, "Translation, Nation Branding and the Indo-Chic," by Belén Martín-Lucas returns to the issue of translation as an important marker of status in the economic and cultural global systems, which plays a crucial role in nation branding and cultural diplomacy. Cultural diplomacy can be defined as a revolutionary approach to international relations consisting of achieving soft power, understood as "the ability to achieve desired outcomes in international affairs through attraction rather than coercion" (Gilboa, 2002) and especially intended to encourage foreign trade. This chapter provides a very articulate description of the machinery behind the selection and promotion of authors for translation. Despite the help of institutional programs, 
the decisions on which texts and which authors get translated are now more than ever before in the hands of the big publishing corporations who often exchange their authors' rights with their sister branches in other countries. Since multiculturalism is one of the most valued characteristics of Canada, both by foreigners and by Canadians themselves, it is precisely in the promotion of qualities like "cosmopolitan" and "multicultural" that the interests of Canadian cultural diplomacy and private publishers' interests coincide.

Despite this fanfare of multiculturalism, in Spain there are few Canadian titles available in translation from racialized writers, and most of them can be identified as prize-winning authors of South Asian origin. The success of authors who are conveniently labelled as "diasporic", "multicultural", or "ethnic" is in great part due to the arduous work of promoting the visibility of subaltern cultural production. However, the commercial exploitation in the cultural market of this privileged group - as compared to other racialized literatures of Canada, such as writing by Aboriginals - has exposed the vigour of a renewed colonial desire for the exotic that some postcolonial theorists like Graham Huggan (2001) have commented on. In the light of these considerations, the main aim of Belén Martín-Lucas' study is to scrutinize the modes of marketing, circulating and reading South Asian fiction from Canada in Spain in order to evaluate how "Canadian" or how "Asian" they are perceived to be by their Spanish audience, and to what extent they participate in or resist the global phenomenon of the Indo-chic. Martín-Lucas critically concludes her chapter by stating that if Canada really intends to be branded as a multicultural nation abroad, greater financial aid should be devoted to the translation and promotion of some relevant authors from visible minority groups - like Black Canadian, Native Canadian and East Asian writers - who, despite their literary value, are still conspicuously absent from the Spanish literary system.

Continuing to draw on notions of nationalism and literature, the chapter "Canadian into Catalan" by Isabel Alonso-Breto and Marta Ortega-Sáez starts out with a comparison of Catalonia and Quebec in what concerns their political situations and socio-cultural realities, in particular in the area of language. This comparison is relevant even in a work which deals only with CanLit in English because of the minority language and distinct nation status of Catalonia and Quebec, two shared attributes which have generated multiple exchanges, including cultural ones. The Bureau du Québec in Barcelona, the only one in Spain, plays a crucial role in the promotion of Quebecois culture in Catalonia (and in the rest of Spain), where Quebecois performers like the Cirque du Soleil, Les Sept Doigts de La Main and Robert Lepage are now well-known. The exhaustive work carried out by the Bureau, described by its cultural officer in an interview with the authors of this chapter, has indirectly had an impact on the visibility of English-Canadian writers in Barcelona, a city which is a significant centre of publishing both in Spanish and in Catalan. 
In the rest of the chapter Isabel Alonso-Breto and Marta Ortega-Sáez analyse trends in the publication of English-Canadian writers into Catalan, classifying the published translations into five groups: (1) literature for children and teenagers; (2) consecrated Canadian authors; (3) multicultural authors (especially South Asian Canadians); (4) Canadian best-sellers and (5) emerging Canadian authors. Anglo-Canadian authors (consecrated or emerging) have so far been translated into Catalan when there is some guarantee of success, especially if sales of their texts have already been tested in Spanish. The authors conclude that the corpus of Anglo-Canadian texts translated into Catalan not only deserves to be appreciated, but can expect to flourish in the coming years. The reasons for this optimism can be found not only in the cultural vitality of Catalonia and the favourable instititutional context, but also in the status of Catalan as a prestigious literarylanguage. Even Bourdieu in his article about the situation of publishing in France ackowledges this status by recounting how publisher Jacqueline Chambon had "discovered" Catalan literature: "I [Chambon] realized that there was a very interesting literature [...] an independent Catalan literature, in the Catalan language, in Catalonia" (Bourdieu, 1999). An established literary system like the Catalan one needs translations of works by prestigious writers to enrich their canon, and given that English-Canadian authors have a rising currency in Spain, the translations into Catalan will probably continue apace.

As its title suggests, Chapter 5 ("A Prince of Asturias Award for the Queen of Canadian Letters: Reading Margaret Atwood's Texts in Spain") by Pilar Somacarrera deals with the circumstances that surround the awarding of this prestigious Spanish literary prize to Atwood and with the way that her texts (her literary texts but also her celebrity "text") have been interpreted. First, I analyse the factors which have influenced the Spanish transference of her writing (titles, publishers and translators). Secondly, I consider the way in which what Richard Dyer calls the "star text" of her literary celebrity has been read in Spain through the study of reviews, articles, notes and interviews published in the press. Atwood was originally imported into Spain, not as a Canadian author, but because of her reputation as an internationally renowned writer. The title chosen for the transference in 1987 was The Handmaid's Tale, a novel of speculative fiction whose subversive depiction of an authoritarian regime found a warm reception in post-Franco Spain, as it responded to the readers' "horizon of expectations" (Jauss). A combination of elements intrinsic to the novel together with some factors related to the target culture guaranteed the success of the book, which opened the way for more Atwood novels to be imported into the Spanish literary system. After Atwood received the Booker Prize in 2000 and the inclusion of her novel Surfacing as one the canonical texts of Harold Bloom's The Western Canon (1994), the Spanish literary system started to promote Atwood more as a canonical writer than as an alternative one. A number of editorial 
and institutional initiatives contributed to her integration in the Spanish literary system, which culminated in 2008 with the Prince of Asturias Award. This prize launched her as a public intellectual in Spain but did not raise the sales of her books, which remain modest and restricted to a group of devoted fans who, increasingly, express their opinions in blogs and websites.

Drawing on reader response theories, Chapter 6 ("A Spanish Passion for the Canadian Short Story"), which I have also authored, looks into the phenomenon of Munro's popularity in Spanish blogs and websites. Munro's success has paralleled a revival of the short story in the Spanish literary system, which has chosen the Canadian writer as a new cosmopolitan model for its novice practitioners. Prestigious members of the Spanish cultural elite like writers Elvira Lindo, Antonio Muñoz Molina and Javier Marías, critics like Professor Fernando Valls and cultural institutions like the Prince of Asturias Foundation have supported Munro by recommending her in literary workshops, reviews, websites and blogs and proposing her for awards, like the Reino de Redonda Award (Marías) or the Asturias Award that Atwood received in 2008. Three Spanish literary blogs specializing in the short story (El sindrome Chejov, El tacto de un billete falso and La luz tenue) have consistently supported Alice Munro and her works in the last five years. Because of the immediacy and accessibility of their medium, blogs have democratized expertise in reviewing, offering new possibilities for subjective and spontaneous interaction between readers. The blogs I have analysed in the chapter present a continuum of responses, from those that are close to professional reviewing to those that are plainly emotional reactions from fans. Responses from some of the bloggers who are professional writers can be read in the light of HansRobert Jauss's "horizon of expectations." They establish a relationship to familiar literary works by comparing Munro to a list of American and European masters of fiction or of the short story. Anonymous readers, on the other hand, often produce impressionistic and emotional responses coloured, as Wolfgang Iser observes, by their own experiences. Even if the phenomenon is tinged by unavoidable self-promotional and/or commercial interests, the Spanish passion for Munro's stories continued to grow following the publication of the translation of her latest short story collection Too Much Happiness in the fall of 2010. This has also been translated into the Catalan and Basque languages.

In the first chapter of the last section of the volume ("Gen X: Culture and Pedagogy"), Mercedes Díaz-Dueñas explores Douglas Coupland's Spanish reception. Coupland presents a special case within the study of CanLit in Spain not only because he has been relatively widely published and reviewed but, most importantly, because his works have helped to change the way in which literature and contemporary culture are perceived. The theoretical framework chosen for this chapter is that of polysystem theory, as it reflects the way in which literature is part of the social, cultural, literary and historical framework. 
The context for publication of Coupland's internationally acclaimed first book is, indeed, crucial to an understanding of his reception in Spain. Generation X was translated in 1993 in the midst of much political and economic unrest. Echoes of this turmoil reached Spanish alternative magazines like Ajoblanco, which in 1994 published a famous article of the same title that clearly contributed to the long-standing popularity of Coupland and his book. In fact, Generation X has had a permanent influence on the way he has penetrated the Spanish literary system, as it is mentioned in every review of Coupland's work in the Spanish press.

In addition, the label Generation $X$ was soon applied to a group of Spanish writers who were publishing their first novels in the nineties and broadly shared the thematic preoccupations and stylistic characteristics of the Canadian writer's works. The protagonists of these novels (both Coupland's and the Spanish writers') are groups of young people who feel alienated and dissatisfied with their lives, and their stories are told in a predominantly oral style, which also favours visual techniques. Spanish literary critics have variously accepted or rejected this label for this group of writers, but most tend to include the following names in the movement: José Ángel Mañas, Gabriela Bustelo, Cuca Canals, Lucía Etxebarria, Ismael Grasa, Ray Loriga, Pedro Maestre, José Machado, Care Santos and Roger Wolfe. Just as Coupland has been criticised or simply ignored by some members of the Canadian literary establishment, these Spanish authors have received harsh treatment at the hands of some Spanish literary critics. In The Cambridge History of Canadian Literature, only five lines of text are dedicated to Coupland in the chapter focusing on comic art and bande dessinée (Gabilliet, 2009). Crude criticism rather than deletion is the approach chosen to describe the Generation X group of Spanish writers in Santos Alonso's book about the Spanish novel of the turn of the century. He refers to their works as "stories that are written in the hope of being turned into films, and collections of pages evoking musical anthologies [which attempt] to convince the young public [...] that this is good literature, instead of the real literature which invites reflection and wisdom (Alonso, 2003).

In the final chapter of the collection ("Home Truths: Teaching Canadian Literatures in Spanish Universities"), Eva Darias-Beautell provides a critical overview of the teaching of Canadian literature in Spanish universities in the past fifteen years from the 1994 curricular reform, within which most current courses on Canadian literature found their place, to the present introduction of new curricular designs in 2009 as part of the Bologna Process. This temporal framework is, therefore, structured around a large reform affecting studies at all European universities and involving a significant epistemological shift. DariasBeautell's analysis focuses on three main interrelated issues. Firstly, she looks into the teaching of Canadian literature from an institutional perspective, including a description of the obstacles found in the process of introducing the new subject 
over the past sixteen years, as well as the difficulties encountered by attempts to situate Canadian literature as independent from "Other/Commonwealth/ Postcolonial" Literatures, on the one hand, and from "American Literature," on the other. Secondly, she examines the contents of a selection of programs of English-Canadian Literature courses taught at university level in Spain. Thirdly, she discusses the teaching methodologies and the theoretical background used in the courses. Most of these courses are taught in English, but the traditional methods of close reading and thematic approach are making a comeback, in the light of the decreasing cultural and linguistic level of Spanish university students. More sophisticated theoretical slants have also been attempted by some Spanish teachers in their syllabi, like feminism, postcolonialism, queer studies and ecocritical studies, especially at Master level courses. Most of these CanLit courses were created thanks to the financial support of the Faculty Enrichment Awards provided by DFAIT, but their development and survival has been - and still is - determined to a large extent by the academic pressures of the institutional contexts in which they originated. During the current Bologna process which implies a large curricular reform aimed at merging with other European universities, these academic tensions are more tangible than ever, and the possibilities for introducing courses specializing in Canadian Literature have been severely restricted. ${ }^{2}$

Darias-Beautell ends her chapter with two open questions: What is the future of Canadian literature in Spain? And what function, as teachers and critics of CanLit, can we have in its development or its evolution? To me, the answer is clear: as academics and cultural ambassadors of Canada, we should disseminate Canadian literature not only in the academic sphere, but also in the wider world outside: in the publishing realm - publishers are gradually becoming more receptive to initiatives coming from translators and academics - in cultural institutions, and in the media. The publication of this volume marks a turning point in the development of English-Canadian literature in Spain and bears witness that Canadian Literature is no longer confined to the space of universities and is venturing beyond the academic walls.

In June 2010, the Canadian Embassy in Spain opened its new offices at Torre Espacio, which, according to its web page, is "one of the most prestigious and emblematic buildings in 21st- century Madrid, from which it will continue to serve Canadians and its Spanish interlocutors with the latest technological advances" (Government of Canada, 2010). The new site of the

2 In 2010 there were no applications from Spanish academics for the Faculty Enrichment Award, the program for Understanding Canada aimed at starting new Canadian Studies courses at Spanish universities. (information provided by the Canadian Mission in Madrid). 
Canadian Embassy at one of the three futuristic towers which symbolize the Madrid of the new millennium is symbolic of the new challenges faced by transference of English-Canadian literature into Spain. How will AngloCanadian literature continue to matter in a media - and technological- age? How will technological advances like the e-book affect the continuity of translations and the reediting of titles that were once published on paper and are now out of print? What is, or will be, the role of social internet networks in the dissemination of English-Canadian authors and their texts? These questions are to be answered in future studies, as English-Canadian writers continue to be read and appreciated in Spain, even if in ways that we cannot foresee at the moment. 